\title{
Research on the Development Process of China's Hotel Industry During the 40 Years of Reform and Opening Up
}

\author{
Xuan Gao \\ International Hospitality Management School \\ University of Sanya \\ Sanya, China 572022
}

\author{
Xiaomeng $\mathrm{Su}$ \\ International Hospitality Management School \\ University of Sanya \\ Sanya, China 572022
}

\begin{abstract}
In the past 40 years of reform and opening up, China's hotel industry has gone through tremendous changes from weakness to strength. At the beginning of reform and opening up, there were only 200 restaurants that foreign guests are permitted to stay in China. After 40 years of development, China's hotel industry has become an industry with considerable scale. This paper mainly looks back how the hotel industry originally dominated by the government and dominated by reception in China has gradually transformed into a comprehensive industry dominated by the market with starred hotels, economy hotels and non-standard hotel industry under the action of market economy. This change laterally reflects the trajectory of the development and progress of hotel industry in China in the past 40 years of reform and opening up.
\end{abstract}

Keywords-hotel industry; reform and opening up; development process

\section{INTRODUCTION}

Since the Third Plenary Session of the Eleventh Central Committee of the Communist Party of China has made the great decision of reform and opening up in 1978, China has entered a new historical period with economic construction as the focus of its work, thus opening the reform and opening up road guided by economic orientation in the new era of tourism reform[1]. Tourism policy has also changed from "political orientation" in former days to epoch-making "economic orientation". In the past 40 years, with the continuous advancement of practice pace of reform and opening up, the development of tourism has made remarkable achievements. It has grown from a small potato in the world tourism market into an important tourist destination and tourists generating country in the world[2]. As of 2016, the destination countries and regions for Chinese citizens to travel overseas have reached 153, the number of outbound tourists has reached 122 million, the outbound consumption has exceeded 100 billion dollars, and the number of inbound tourists received has reached 138 million[3].

With the rapid development of tourist industry, the hotel industry that converges food, accommodation, travel, tourism, shopping, entertainment and other major elements in tourism activities, has also made remarkable process[4]. The number of starred hotels has not only increased from about 140 in the preliminary stage of reform[5] to 10645 in $2017^{1}$, and the overall business capacity and management level are greatly improved because of the influence of international hotel management groups[6]. The purpose of this paper is to roughly analyze the historical development and structural changes of the hotel industry in the past 40 years of reform and opening up in China.

II. HistoriCAL REVIEW OF THE DEVELOPMENT OF CHINA'S HOTEL INDUSTRY IN THE PAST 40 YEARS OF REFORM AND OPENING UP

From the perspective of the basic process of 40 years reform and opening up of China's hotel industry, its main feature is that it is always at the forefront of China's reform and opening up, and it is prior to carry and try as the ice breaking industry of reform and opening up. The reform and opening up of China's hotel industry in different periods not only effectively settles the problems that restrict the development of the hotel industry, but also effectively levers the reform and opening up in other fields by the reform and opening up of China's hotel industry

In the preliminary stage of reform and opening up, limited by various conditions, there are only 137 hotels in China that could receive overseas guests and the number of guest rooms is only more than 20000 . With the implementation of reform and opening up policy, the development of economy makes the tourism industry receive unprecedented attention. In this context, the rapid development of the national hotel industry has contributed to the increase of the number of hotels and the improvement of service and management levels. It can be seen that the course of its development can be divided into four stages: preliminary development stage (1978-1992), absorption and adjustment stage (1993-2001), and comprehensive development stage (since 2002).

\section{A. Preliminary Development Stage (1978-1992)}

The policy of "opening to the outside world, invigorating the domestic" adopted at the Third Plenary Session of the

Ministry of Culture and Tourism of the People's Republic of China, Statistical Bulletin of National Starred Hotels in 2017. 
China's hotel industry from political orientation to economic orientation[11].

In the early stage of reform and opening up, "earning foreign exchange" was an important goal for vigorous development of tourism. At that time, the policy was to give priority to inbound tourism, and it "did not advocate, publicize or oppose" domestic tourism. Therefore, in order to meet the accommodation standards of international tourists and improve the service and management levels, the National Tourism Administration in 1988 issued the Regulations of the People's Republic of China on Star Rating of Foreign-related Tourism Hotels and the Standards of the People's Republic of China on Star Rating of Foreign-related Tourism Hotels[12] with reference to the international standards and combined with the national conditions. This was the beginning of the standardization of China's hotel industry, which effectively improved the supply quality of China's tourism products, solved the problem of insufficient reception capacity, and promoted the rapid development of inbound tourism. During this period, the number of hotels in China increased dramatically, from 137 in 1978 (more than 20000 guest rooms) to 1500 in 1988 (220000 guest rooms).

During this period, the characteristics of the development of China's hotel industry were mainly manifested that Sinoforeign joint venture hotels were dominated by "foreign capital of overseas Chinese" and the construction of large-scale tourist hotels in major tourist cities. At the same time, the hotel industry also achieved two changes: one was the transformation from entertained state-owned hotels to operating joint venture hotels; the other was the transformation from administrative management dominated by government to enterprise management dominated by market[13].

\section{B. Absorption and Adjustment Stage (1993-2001)}

In 1992, Comrade Deng Xiaoping made it clear in his speech on his southern tour that "the name of reform and opening up was" 'society' rather than 'capital', and reform and opening up must be carried out unswervingly." Under such a background, China's hotel industry began to establish its own hotel management companies and hotel groups, and carried out a large number of references and imitation of the management and administration mode of foreign hotel groups or management companies. Accordingly, the number and scale of China's hotel industry entered a period of swift growth and expansion.

At the same time, China's hotel industry was also constantly learning and imitating the advanced management technology and investment methods in foreign countries. For example, room reservation changed from being processed by telephone or at the front desk to adopting the computer network. After 1990, more than half of the five-star hotels adopted the computer-based automatic management mode to replace the original manual management mode (Lu Junliang, Yang Mingkui, 2004)[8]. With the increasing number of overseas tourists, the mode of credit card payment was gradually accepted by major hotels. The hotel management model can be divided into three types: Sino-foreign joint 
venture, entrusted operation and chain operation (Xu Shiming, 2008)[9].

With the vigorous development of inbound tourism, domestic tourism was also on the rise, and the demand for hotels was increasing. However, the high price of foreign hotels was not affordable for domestic tourists. In order to pander to the consumption capacity of general public, the domestic hotel market also made corresponding adjustments. A large number of one-star, two-star and three-star hotels, that is, medium and low-end hotels, also joined the ranks of the tourism market (Zhang Zhen, 2006)[10]. During this period, the number of starred hotels increased from 1500 in 1988 to 3248 in 1998 (Xu Jingsheng, 2018)[6].

After 1998, affected by natural and man-made disasters such as the Asian financial crisis, flood disaster, international terrorist events, SARS and bird flu, and the ever-expanding competitive advantages of international hotel groups, China's hotel industry began to fall into the dilemma of operation and management (Zhang Deming, 2000)[11], and the whole industry suffered losses for seven consecutive years (Zhao Huanyan, 2014) [7]. This situation forced the China's hotel industry into a stage of adjustment. In the face of adversity, China's hotel industry realized that although it was necessary to continue to learn the experience and mode of foreign hotels, this kind of learning cannot only copy and imitate blindly, but more importantly, it was necessary to constantly think about the amount of money and exploration in the practical operation, created a set of management methods that were suitable for the national conditions and the culture of its own enterprises, so as to open a new situation (Jiang Xin, 2006)[12].

In the continuous thinking and exploration, people gradually realized that conglomeration would be the inevitable road for the future development of China's hotel industry. Local hotel enterprises should get rid of the shackles of traditional models by means of alliance between giants, making their respective advantages complementary to each other, market rules of survival of the fittest, etc.; establish strategic thinking and accept the challenges from all sides through intensive management, advanced management and bold innovation(Zheng Fengping, 2006) [13]. These thoughts and ideas played a very important role in guiding the China's hotel industry to walk out of predicament and develop healthily at that time. At the same time, in order to assist the operation and management of the domestic hotel industry, the National Tourism Administration approved the establishment of 16 hotel management consultation companies in 1993.

This period was the stage when China's hotel industry developed into modernization, and it was also the running in period when all market elements were integrated to form the characteristics of the hotel industry. The characteristics of this period were mainly reflected in the rapid integration of domestic hotel management with the management mode of world-famous chain groups, the development of hotel industry completed the transformation from quantitative change to qualitative change, and the bearing capacity of the market became the only indicator of the development of industry. The hotel industry realized two other changes: one was the transformation from each fights his own battle to standardization; the other was the transformation from decentralized operation to conglomeration, chain-orientation and specialization.

\section{Comprehensive Development Stage (Since 2002)}

Since 2001, China's accession to the WTO, the Beijing Olympic Games, the Guangzhou Asian Games, the Nanjing Asian Youth Games, the Changchun Asian East Games, the Shanghai World Expo and the International Import Expo has made China's economy prosperous. International famous hotel groups one after another are optimistic about the excellent environment of China's economic development, and have accelerated the pace of expansion in China. At present, there are as many as 500 foreign-funded hotels that are "entrusted operation" and "co-marketing contract operation". When China's local hotel industry just comes out of the downturn, it also directly catches up with the more furious international market competition in the era of knowledge economy. Under the severe market environment of "international competition internalization, domestic competition internationalization", China's hotel industry withstands the pressure, meets the challenges, and emerges a large number of local famous hotel brands, such as Shanghai Jinjiang, Beijing Jianguo, Nanjing Jinling, Hunan Huatian, etc., which can compete with international hotel brands. In the process of continuous competition with the international market, the level of operation and management of China's hotel industry is constantly improving, and the overall operation strength is constantly increasing.

During this period, the characteristics of the development of China's hotel industry are mainly manifested that China's hotel industry moves towards the standardization and normalization on production standards, moves towards the development of collectivized management in organizational form, shifts from high profit period to low profit period in revenue, and transits from empirical type to standardization and then to personalization in service type. In addition, the hotels with connotative development aiming at "improving the quality of enterprises", "forging brand recognition" and "improving the competitiveness of the industry" have become the current mainstream.

\section{THE IMPACT OF REFORM AND OPENING UP ON THE STRUCTURAL CHANGE OF THE HOTEL INDUSTRY}

Reform and opening up has opened up the new situation of China's modern hotel industry. After 40 years of development, China's hotel industry has taken place tremendous changes.

\section{A. China's Starred Hotels Are Beginning to Reveal Innovation Inking Under the Four Falls and Four Rises and the Constraints of Laws and Regulations}

Thanks to the reform and opening up, China's hotel industry has gradually become an industry. After the continuous growth from 1978 to 2009, the number of starred hotels in China has slowed down in recent years and entered the adjustment period ("Fig. 1"). 
Variation diagram of the number of starred hotels in China from 1978 to 2017

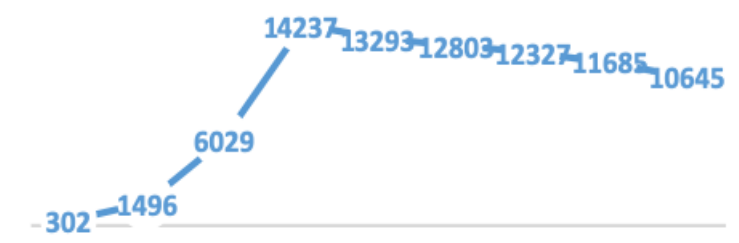

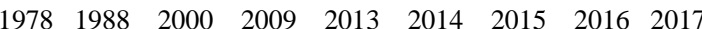

Fig. 1. Variation diagram of the number of starred hotels in China from 1978 to $2017^{3}$.

After the formation of modern hotel industry in China, it has gone through four landslides. The first was the imbalance between supply and demand in 1989, the second was the Asian financial crisis in 1996, the third was the international financial crisis and the post-Olympic effects in 2008 , and the fourth was the post-2013[15]. As for the first three industry crises caused by market volatility, as the time goes on and the market adjusts, China's hotel industry has gradually recovered without changing the demand structure. The fourth industry crisis was caused by the change of demand structure, which was essentially different from the first three times. China's hotel industry must seek supply side reform to deal with. According to the data, China's starred hotels began to recover gradually in 2016 and reversed the situation of negative profit ("Fig. 2"). But "official business and public money consumption" can no longer occupy the dominant position in the hotel consumption structure, instead of lifestyle consumption, and personal payment has become the mainstream consumption mode.

Profit variation diagram of starred hotels in China from 2012 to 2017 (Unit: 100 million Yuan)

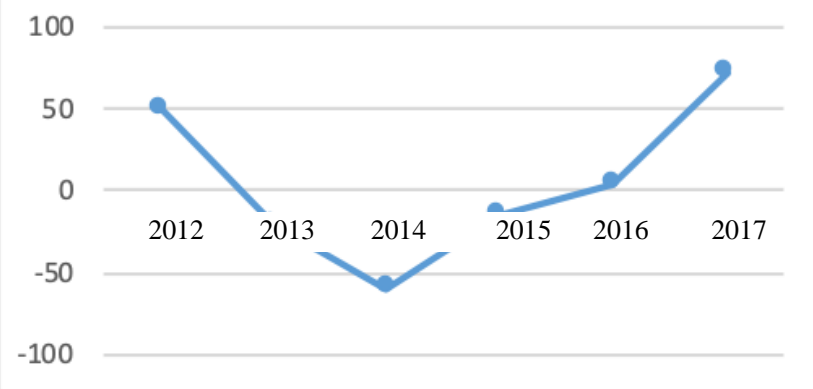

Fig. 2. Profit variation diagram of starred hotels in China from 2012 to $2017^{4}$.

Liang Zhongzheng. Reflection on supply side reform of China's hotel industry [C]. 2017 China tourism science annual conference memoir, 2017-04-22; Ministry of Culture and Tourism of the People's Republic of China, Statistical Bulletin of National Starred Hotels in 2017

$4 \quad$ Ministry of Culture and Tourism of the People's Republic of China, Statistical Bulletin of National Starred Hotels in 2012-2017
It is worth noting that although the national starred hotels have broken through the embarrassing situation of negative profit since 2016 and have increased significantly in 2017, however, "Table I" shows that the number of starred hotels in China is still in a downward trend from 2016 to 2017. This shows that the recovery of starred hotels in China does not rely on the scale, but on the reform of products and the reform of marketing ideas, which corresponds to the rise of occupancy rate, especially the five-star hotels ("Table II").

TABLE II. StatisticAl TABLE OF ChINA'S STARRED Hotel OCCUPANCY RATE FROM 2015 TO $2017^{5}$

\begin{tabular}{|l|l|l|l|}
\hline \multicolumn{1}{|c|}{ Year } & \multicolumn{1}{|c|}{$\mathbf{2 0 1 5}$} & \multicolumn{1}{c|}{$\mathbf{2 0 1 6}$} & \multicolumn{1}{c|}{$\mathbf{2 0 1 7}$} \\
\hline $\begin{array}{l}\text { Average occupancy rate of } \\
\text { five-star hotels }(\%)\end{array}$ & 56.41 & 58.57 & 61.43 \\
\hline Average occupancy rate (\%) & 54 & 54.73 & 54.8 \\
\hline
\end{tabular}

In the development process of starred hotels in China, it is necessary to mention the formulation and improvement of relevant laws and regulations. Since the establishment and implementation of star standard rating system for tourist hotels (hereinafter referred to as "star standard") in 1988, the star standard has gone through four revisions in 1993, 1997, 2003 and 2010, which is referred to as "four standard era". The 2003 edition of "Star Standard" replaces foreign-related hotels with tourist hotels; the 2010 edition of "Star Standard" proposes two categories and six directions. In June 2018, the Ministry of Culture and Tourism issued a document indicating that a new round of revision of "Star Standard" will be launched. There is no doubt that every revision of "Star Standard" reflects the latest development dynamics and trends of China's hotel industry, and is also an important institutional guarantee for the innovation of China's hotel industry under new circumstances.

\section{B. After Rapid Development, Economy Hotels Have Entered into Collectivized Operation, and the Middle-end Hotels Have a Strong Momentum}

$\mathrm{Xu}$ Zurong, born in the 1950s, founded Jinjiang Inn in 1996 that was China's first economy hotel inspired by American motels. Soon afterwards, the first Home Inn and the first Hanting Hotel were established in 2002 and 2005 respectively. For the first time, this kind of simple and fairprice-hotel that was different from the traditional starred hotel emerged in China. China's economy hotel achieved favorable benefits at the beginning of its establishment and reached its peak around 2010. Jinjiang Inn, Hanting, Home Inn, etc. have been actively swarming into the capital market after chain's management. After a round of mergers and acquisitions, restructuring and upgrading, the domestic hotel market in China has for the moment formed an oligopolistic market of three magnates of Jinjiang International, BTG Homeinns Group and Huazhu Group ("Table II").

After the blowout development, China's economy hotels have one after another begun to upgrade. In 2016, Jinjiang

\footnotetext{
5 Ministry of Culture and Tourism of the People's Republic of China,
} Statistical Bulletin of National Starred Hotels from 2015 to 2017 
Group respectively purchased the Groupe du Louvre, Plateno Group and Vienna Group at home and abroad; Huazhu Group and BTG Homeinns Group have also cultivated their own medium- and high-end brands in the way of new construction or acquisition, such as Huazhu's All Seasons, Orange Crystal, and BTG Homeinns Group's Homeinns Choiceness. The reason is that the middle-end hotels in the transformation of economy hotels benefit from the double promotion of consumption ability and service requirements, which is closely related to the development of China's economy, the improvement of national income and the upgrading of consumption since the reform and opening up.

\section{The Rise of Non-standard Accommodation Kicks off China's Hotel Industry Revolution}

The national 13th five-year plan for tourism clearly states that "China will encourage the development of new forms of hotel industry, such as self-driving and motor caravan camps, tent hotels and guesthouse, and build the new type of hotel industry." In 2016, the non-standard hotel industry has witnessed rapid development, with a dizzying speed. The new type of business of various forms, such as guesthouse, inns and so on, has constantly overturned consumers' perception of accommodation.

In the non-standard hotel industry, guesthouse is without question one of the most representative subdivided type of business. In the vast rural areas, the emergence of guesthouse echoes the national policy of targeted poverty alleviation and beautiful rural construction; for entrepreneurs, guesthouse is a superexcellent choice, which greatly drives the entrepreneurial passion of the society; at the same time, with its charm, guesthouse will attract more and more people from the city to the countryside, which unconsciously promotes the counterurbanization.

\section{CONCLUSION}

Looking back the history of 40 years, it can comprehend the historical development and change of China's hotel structure in the process of opening to the outside world through the development and structural change of China's hotel industry and the promulgation of the legal system and norms of the hotel industry. Due to the entry of foreign-funded hotels into the market, the improvement of living standard of people and the increase of income, the consumers' requirements for the environment, health, safety and comfort of the hotel are also increased, and the demands for multi-functional services (such as catering, conference, exhibition, entertainment, etc.) are more stringent. At the same time, with the advent of the information age, consumers will master more and more information about their consumption. As the hotel management guided by the market economy, it is necessary to reveal a high degree of professionalism in the face of customers in order to win the trust of mass consumers.

In current China's hotel market, the types of business are more diversified and the products are more complete. Although the competition in the hotel industry has been inevitable, in the era of "opportunities coexist with threats", the hotel industry will continue to prosper along the mechanism of market economy whether in the face of domestic tourism or foreign inbound tourism wave. In the future, any enterprise that invests in China's tourism industry or hotel operation must be familiar with the development trend of China's hotel industry in the future:

First, China's hotel industry shall unswervingly continue to deepen the reform and opening up policies. The development process of reform and opening up in the past 40 years shows that opening to the outside world is the magic weapon for the survival and development of China's hotel industry. China's hotel industry must continue to stick to an open attitude and assimilate the achievements of economic globalization in an inclusive manner.

Second, the future competition of the hotel industry is essentially the competition of the satisfaction degree of the hotel to the customer needs and wants. With the development of technology and the gradual maturity of consumers, the price consumption has gradually changed to the value consumption. In such an external environment, China's hotel industry, especially the traditional starred hotels, must transform the product design and marketing ideas, in order to effectively walk out of the low tide.

Third, technology cannot replace the milk of human kindness. The hotel industry actively seeks to integrate with the Internet, but we should make it clear that the hospitable reception spirit is the most significant feature of the hotel industry, which will not be easily replaced and is still the core ideology that China's hotel industry should adhere to.

Fourth, the conglomeration trend of China's hotel industry is gradually strengthened, and capital is often the last thing to laugh at. The hotel brands in China should realize that actively participating in the capital market and promoting the integration between groups is conducive to the formation of economies of scale and the overall strength of the industry.

\section{REFERENCES}

[1] Zeng Bowei. 40 Years of Reform and Opening Up: the Evolution of China's Tourism Development Orientation [n]. China Tourism Daily, October 9, 2018 (003) (in Chinese)

[2] Xia Jiechang, Xu Jinhai. 40 Years of Reform and Opening Up of Tourism Industry in China: Review and Prospect [J]. Economic and Management Research, 2018, 39 (06): 3-14 (in Chinese)

[3] Liu Yuanyuan. Rapid Development of Tourism Industry in China in 2017 [N]. Chinese People's Political Consultative Conference Daily, December 22, 2017 (009) (in Chinese)

[4] Huang Hongying. Analysis of the Development Prospect of Hotel Industry in China in the 21st Century [J]. Jiangxi Social Sciences, 2001 (07): $163 \sim 164$ (in Chinese)

[5] Ma Yong, Li Lixia. Review and Prospect of the Development of Hotel Industry in China in the 30 Years of Reform and Opening Up [J]. Journal of Beijing International Studies University, 2009,31 (01): $1 \sim 6$ (in Chinese)

[6] Xu Jingsheng. Tourism Hotel Industry: the Leading Industry of Reform and Opening Up (I) [N]. China Tourism Daily, October 11, 2018 (008) (in Chinese)

[7] Zhao Huanyan. 30 Years' Review and Thinking of Chinese Hotel Industry [J]. Hotel Modernization, 2014 (03): $63 \sim 66$ (in Chinese) 
[8] Lu Junliang, Yang Mingkui. How Does the Hotel Management Information System Face E-commerce [J]. Information and Computer, 2004 (07): $35 \sim 38$ (in Chinese)

[9] Xu Shiming. Research on the Development of Five-Star Hotels in China [D]. Tianjin: Tianjin University, 2008 (in Chinese)

[10] Zhang Zhen. Research on the Management Strategy of Chinese Economic Hotels [D]. Hefei: Anhui University, 2006 (in Chinese)

[11] Zhang Deming. The Integration of Eastern and Western Civilizations and the Development of Asia Pacific Economy: New Exploration on the Causes of Asian Economic Miracle and Financial Crisis [J]. World History, 2000 (06): 78-86 (in Chinese)

[12] Jiang Xin. Confucian Businessman Spirit and Localization of Hotel Management [J]. Journal of Guilin Tourism University, 2006 (02): 197199 (in Chinese)

[13] Zheng Fengping. Accelerate the Process of Conglomeration to Enhance the Competitive Strength of China's Hotel Enterprises [J]. North Economic and Trade, 2006 (06): $88 \sim 89$ (in Chinese)

[14] Liu Wei. Hotel Management (Second Edition) [M]. Beijing: China Renmin University Press, 2018.23-25 (in Chinese)

[15] Zhang Rungang. A Warmer Market and A New Era of Hotel Industry [N]. China Tourism Daily, 2017-12-07 (A02) (in Chinese) 